\title{
O sório Cezar e Roger Bastide: as relações entre arte, religião e psicopatologia
}

\author{
Paulo Dalgalarrondo \\ G uilherme G utman \\ Ana Maria Galdini Raimundo 0 da
}

Este artigo trata de dois momentos históricos dos estudos sobre as relações entre arte, religião e psicopatologia; neste sentido, analisamos os textos "A arte primitiva nos alienados" (Osório Cezar, 1924) e "Pintura, loucura e cultura" (Roger Bastide e Osório Cezar, 1956).

No Brasil, Osório Cezar, médico do Hospital de Juquery, foi o primeiro pesquisador a tomar como objeto de estudo a arte produzida por doentes mentais.

Roger Bastide, intelectual francês que viveu no Brasil, um autor prolífico, entre outras relevantes contribuições legou-nos estudos seminais nos campos da sociologia das doenças mentais e da etnopsiquiatria.

Palavras-chave: Arte e loucura, religião e psicopatologia, Roger Bastide, Osório Cezar 


\section{A arte dos alienados como objeto de estudo}

Surgem em fins do século XIX, e sobretudo nas primeiras décadas do $\mathrm{XX}$, as primeiras publicações médicas sobre as manifestações artísticas dos doentes mentais, tais como as de Cesare Lombroso (Genio e follia, 1864), P. Max Simon (Les écrits et les dessins des aliénés, 1888), Rogues de Fursac (Les écrits et les dessins dans les maladies nerveuses et mentales, 1905), Marcel Réja (L'art chez les fous, 1917), H. Prinzhorn (Bildnerei der Geisteskranken [Desenhos de alienados], 1922), Honorio Delgado (El dibujo de los psicopatas, 1922), Morgenthaler (Ein Geisteskranker alskunstler [Um artista alienado], 1925) e J. Vinchon (L'art et la folie, 1925) (Cezar, 1951; Dalgalarrondo, 2006).

No Brasil, temos os trabalhos pioneiros do médico e crítico de arte Osório Cezar, do Hospital de Juquery (São Paulo), que publicou em 1924 o artigo “A arte primitiva nos alienados”. Tudo indica que, no país, ele foi o primeiro estudioso a dedicar-se de forma sistemática e aprofundada à análise tanto da arte produzida por doentes mentais quanto das manifestações religiosas e culturais da população abandonada nos hospícios. $^{1}$

Contemporâneo de Ulysses Pernambucano (1892-1943)² - e de suas experiências inovadoras à frente do hospital psiquiátrico da Tamarineira, em Recife - e antecedendo, ainda que com um enfoque bem distinto, as realizações de Nise da Silveira (1905-1999) ${ }^{3}$ no Centro Psiquiátrico do Engenho de Dentro, no Rio de Janeiro, Osório Cezar fez em São Paulo as primeiras junções entre psiquiatria, arte e psicanálise.

1. Vale mencionar uma única obra: Manifestações artísticas nos alienados (1923), de Silvio Aranha de Moura, cujo pioneirismo e interesse fizeram valer uma citação de Cezar em seu A expressão artística nos alienados (1929).

2. Sobre a atuação reformadora de Ulysses Pernambucano, veja-se Pereira, M. E. C. Ulysses Pernambucano e a questão da 'Higiene Mental'. Revista Latinoamericana de Psicopatologia Fundamental, ano VIII, n. 1, p. 123-29, mar./2005.

3. Nise da Silveira começaria seu conhecido trabalho com terapia ocupacional e artes no Centro Psiquiátrico do Engenho de Dentro depois de 1944. Consultar Carvalho, S. M. M., Amparo, P. H. M. Nise da Silveira: mãe da humana-idade. Revista Latinoamericana de Psicopatologia Fundamental, ano IX, n. 1, p. 126-37, mar./2006. 
Considerando a importância dessa contribuição, relativamente desconhecida e pouco estudada, ${ }^{4}$ a seção História da Psiquiatria republica neste número dois textos de Osório Cezar, o primeiro sendo o já citado “A arte primitiva nos alienados” (1924) e o segundo, em co-autoria com Roger Bastide, intitulado "Pintura, loucura e cultura" (1956).

\section{Osório Cezar}

Osório Cezar (1895-1980) nasceu na cidade da Paraíba (PB), capital do Estado, mais tarde chamada João Pessoa. Veio para São Paulo em 1912 cursar odontologia, em que se formou em 1915 (Ferraz, 1998). Mais tarde, em 1925, formou-se em medicina na Faculdade do Rio de Janeiro; desde 1923, era estudante de medicina interno no Hospital de Juquery (São Paulo), passando a trabalhar ali como médico desde o ano de sua formatura até sua aposentadoria, em 1965 (Andriolo, 2003).

Quando conclui, aos trinta anos de idade, a faculdade de medicina, sua primeira especialização não foi, como poderia se pensar, a psiquiatria, mas a anatomia patológica. Mostra deste seu interesse inicial pela investigação em anatomia patológica, bem como das implicações destas pesquisas para a clínica psiquiátrica, é um extenso artigo chamado "Contribuição para o estudo das glândulas de secreção interna na demência precoce” (1928/1929). Ali, ao lado de revisão das pesquisas realizadas sobre as possíveis relações entre disfunções das glândulas endócrinas (tireóide, supra-renais, ovários e testículos) e a patogenia da demência precoce (chamada de esquizofrenia por E. Bleuler), o autor publicou os resultados de suas pesquisas pessoais, inclusive com figuras mostrando cortes histológicos realizados por ele. Mais do que o resultado, interessa aqui apontar o estilo cuidadoso do pesquisador, preocupado em estudar in loco e empiricamente as grandes e controversas questões colocadas à psiquiatria da época.

A arte fez parte de sua vida desde cedo; Osório Cezar tocava violino quando recém-chegado a São Paulo, chegou a sustentar-se dando aulas particulares do instrumento - e desde as suas primeiras experiências no Juquery interessou-se pelos trabalhos de arte dos pacientes ali internados (Ferraz, 1998). Entre Rio e São Paulo, ainda durante os anos de estudante de medicina, Osório teve

4. Sobre a marcante originalidade de toda a obra de Osório Cezar, em particular os seus estudos sobre a produção artística dos sujeitos com transtornos mentais, assim como a organização de oficinas de arte, a pedagogia artística livre e o engajamento na reabilitação social, ver o livro de Maria Helena C. Toledo Ferraz, de 1998. 
em mãos dois livros que o impressionaram muito - Bildnerei der Geisteskranken do alemão H. Prinzhorn e L'art et la folie do francês J. Vinchon. Essas obras foram responsáveis, nas palavras dele, pela "idéia de estudar a arte dos alienados, comparando-a com a dos primitivos e a das crianças” (Cezar, 1929, p. xxi).

Nas décadas de 1920-1930, o Hospital de Juquery funcionava nos moldes de um "asilo-colônia”, isto é, aplicava um modelo assistencial no qual o trabalho - inclusive o trabalho manual e artístico - era compreendido como um importante instrumento terapêutico. É importante lembrar que, à época, não havia ainda os recursos farmacológicos que surgiriam apenas a partir dos anos 1950, e que os “tratamentos biológicos” aplicados até então - como, por exemplo, o coma insulínico - eram pouco eficientes, além de potencialmente perigosos para os pacientes. Neste contexto, a terapia pelo trabalho gozava de grande prestígio, como fica evidente nas palavras do próprio Osório Cezar (1929): “O regime do trabalho moderado entre os alienados tem sido preconizado com ótimo resultado. $\mathrm{E}$, entre nós, justiça seja feita, este método terapêutico tem sido usado com excelente proveito” (p. 2).

Naturalmente, nem tudo eram flores no Juquery. Sabemos hoje, mais do que se sabia à época, quanto os hospícios em geral foram palco de tratamentos equivocados, de aglomerados humanos em condições precárias e de episódios tristemente freqüentes de descaso com a população internada. Nessa vertente, Osório Cezar não chegou a ser um contestador do regime psiquiátrico vigente, ${ }^{5}$ mas teve sensibilidade suficiente para ver naquilo que alguns contemporâneos entendiam como "rabisco de maluco”, realizações artísticas que mereciam atenção e, eventualmente, considerou os trabalhos como sendo de alta qualidade e expressividade.

Tal sensibilidade permitiu que ele criasse uma Seção de Artes Plásticas mais tarde, Escola Livre de Artes Plásticas do Juquery - na qual os internos tinham condições mais adequadas para a atividade de criação e um espaço voltado para a convivência em torno da produção de cunho artístico, substituindo o caráter mais rígido e mecânico do modelo de ergoterapia, até então em prática.

A psicanálise absorveu Osório intensamente: em 1927, foi um dos membrosfundadores da Sociedade Brasileira de Psicanálise (SBP), a primeira da América Latina, criada em São Paulo, sob a presidência de Francisco Franco da Rocha. Em 1928, encontramos Osório Cezar entre os presentes na reunião em que se

5. Vale observar que tomar Osório Cezar como reformador do modelo assistencial psiquiátrico seria um anacronismo, uma vez que, em âmbito internacional, nas primeiras décadas do século XX, até perto da Segunda Guerra Mundial, o questionamento aos grandes hospitais como centro da assistência aos doentes mentais não se colocava, apenas reclamavam-se melhorias em suas condições de vida e na assistência médica aos internos. 
fundava o núcleo do Rio de Janeiro da SBP, que seria presidido por Juliano Moreira (Oliveira, 2005).

Ainda em 1927, ele receberia uma carta de ninguém menos que Freud, o qual agradecia a remessa de um trabalho de Cezar editado na revista Memórias do Hospício de Juquery. Nesta carta, lê-se: "Causa-me grande satisfação a prova de interesse que a nossa psicanálise vem despertando no seu distante Brasil e apresento-lhe os meus protestos de estima e consideração” (Freud, 1927 apud Nosek, 1994, p. 87).

Entre 1940 e 1960, O. Cezar atuou de forma constante como crítico de arte, publicando em jornais de grande circulação, como o Estado de S. Paulo, Folha da Noite, Folha de S. Paulo etc. (Ferraz, 1998). Também tinha relações pessoais próximas com artistas modernistas, como Mário de Andrade e Tarsila do Amaral, tendo sido ela companheira de Osório ${ }^{6}$ no início dos anos de 1930.

Além da arte, da psicanálise e da psiquiatria ainda houve lugar para mais um campo de interesse de Cezar, a militância política. A paixão pela arte, o interesse genuíno pela psicanálise - que não gozava, então, do prestígio que viria a ter nas décadas de 1960 e 1970 - e o posicionamento político à esquerda faziam de Osório Cezar um personagem de perfil libertário.

Por esta razão, parece ter sido alvo fácil da polícia política de Getúlio Vargas, sendo preso várias vezes, duas delas ao retornar de viagens à União Soviética; na primeira, em 1932, ficou detido durante um mês no Rio de Janeiro. Em 1935, após participar do XV Congresso Internacional de Fisiologia, em Moscou, foi preso no navio que o trazia ao Brasil (Ferraz, 1998). Ele escreveria dois livros

6. A relação entre eles durou pouco tempo, mas a convivência e as idéias marxistas dele incidiram sobre a obra da pintora Tarsila, que passou a pintar temas de cunho mais social. Cezar, por sua vez, na década de 1950, já distante do seu convívio, escreveu para um jornal uma crítica apaixonada sobre o trabalho dela.

A respeito de suas primeiras impressões sobre Osório Cezar, disse Tarsila: “Achei-o inteligente, gostei da forma espontânea, bem própria do nordestino, de dizer com franqueza seus pontos de vista” (Amaral, 1975, p. 299). Da parte dela, certamente, não houve entre eles, o que se chama de amor à primeira vista. Já do lado dele, a impressão que fica é outra: “(Eu) era muito mocinho, chegara havia pouco de São Paulo, eu tocava violino, ela me olhou sorrindo enquanto eu tocava, eu estremeci todo... Tarsila era uma beleza, e não somente isso, tinha uma cultura humanística como raras pessoas possuem, e além do mais era suave, boa” (Amaral, 1975, p. 339).

Ambos os depoimentos são bem ilustrativos do que cada um representou para o outro naquele início de anos 1930. Para Tarsila, aquele jovem psiquiatra representava "um salto para o futuro" - uma espécie de abertura para uma face do mundo que, a ela, surgia com o ar de novidade. Para Cezar, ela - que à época já era ícone vivo do movimento modernista concretizava a inclusão da arte em sua vida. 


\begin{tabular}{cccccc|l}
$R \quad E \quad V$ & I & T & $A$ \\
LATIN O A M ERIC A N A & \\
DE PSICO PATO LOGIA & \\
F U N D A M E N T A L & \\
ano X, n. 1, mar/ 2007 & \\
\hline
\end{tabular}

inspirados pela experiência da viagem de 1932: Onde o proletariado dirige (1932) e Que é o estado proletário? (1933), sendo o primeiro com ilustrações da então companheira, Tarsila.

A franqueza plena e a postura afirmativa que Tarsila do Amaral identificou nele, o misto de idealismo científico e vontade política, a voracidade pelos livros e pelo trabalho deram origem a obras nas quais, sem dúvida, mesclam-se todos esses ingredientes. Como disse Mário de Andrade, suas maiores qualidades eram a "atitude nítida, o fervor com que defendeu a sua causa, e a lucidez com que o soube fazer” (Andrade apud Amaral, 1975, p.375) - e, valeria acrescentar, o seu pioneirismo.

\section{Principais publicações de Osório Cezar}

Em 1924, O. Cezar publicou “A arte primitiva nos alienados”, ora republicado, de que falaremos adiante. Em 1927, em colaboração com J. Penido Monteiro, editou um ensaio chamado Contribuição ao estudo do simbolismo místico nos alienados (Cezar e Monteiro, 1927) e, no mesmo ano, um artigo em parceria com o psicanalista Durval Marcondes, "Sobre dois casos de estereotipia gráfica com simbolismo sexual”, onde apresentaram cinco figuras reproduzindo desenhos de dois doentes mentais e usaram as teorias de Freud e Jung, considerando que o simbolismo onírico freudiano teria correspondência nos simbolismos gráficos encontrados nos casos estudados (Marcondes e Cezar, 1927).

Foi recolhendo o material produzido pelos internos - desenhos, pinturas, esculturas, objetos e escritos - que Cezar seguiu elaborando suas reflexões e análises, algumas amplamente fundadas na psicanálise, e presentes em um de seus livros mais importantes: A expressão artística nos alienados, de 1929. A escuta interessada parecia ser sua postura costumeira, o que lhe permitia recolher materiais tão ricos em sua prática como psiquiatra: "Quem entrar num manicômio e procurar conversar atentamente com os doentes, ouvir com interesse as suas queixas, as suas curiosas histórias, notará que, entre eles, a imaginação, por vezes, é exuberante” (Cezar, 1929, p. 1).

Dez anos mais tarde, Cezar (1939) publicou um outro importante livro, inteiramente dedicado a aspectos religiosos relacionados à doença mental, intitulado Misticismo e loucura, ${ }^{7}$ pelo qual recebeu, em 1949, prêmio da Academia Nacional de Medicina (Ferraz, 1998, p. 40). Nesse trabalho, o psiquiatra paulista faz

7. O livro foi também publicado em espanhol como Misticismo y loucura. Buenos Aires: Paternos, 1945 (Ferraz, 1998). 
inicialmente uma análise etnopsicológica do caráter religioso dos brasileiros, sobretudo de negros e mestiços. Nesses capítulos iniciais, Cezar apóia-se em teses que já se tornavam obsoletas na época: o evolucionismo cultural e a noção de primitividade de certos grupos raciais (negros e índios).

No capítulo "Fanatismo e psicopatia” ele relata uma série de "loucuras religiosas epidêmicas” ocorridas no Brasil. Analisa o episódio de Pedra-Bonita, em Pernambuco, em que morreram algumas dezenas de pessoas, movidas pelo delirante João Santos, que acreditava haver descoberto uma área sagrada prenhe de riquezas e maravilhas celestes, onde ainda reinaria o legendário rei português, Dom Sebastião. No episódio várias pessoas se suicidaram e ocorreram muitos sacrifícios humanos, na busca por aquele éden agreste. Relata ali também a então chamada loucura epidêmica de Canudos, liderada pelo místico (considerado também delirante) Antonio Conselheiro. Ainda como expressão de devoção extremada e de contornos delirantes, cita o grande líder religioso nordestino Padre Cícero do Crato (e de sua Juazeiro) como exemplo de santo popular, autor de muitos milagres (e assim, substrato de delírios religiosos coletivos).

Parece-nos que o capítulo mais original dessa obra de Osório Cezar é o último, sobre “Os místicos dos hospícios”. Ali ele descreve como as diferentes patologias mentais produzem delírios e alucinações de conformação religiosa. Afirma que é a parafrenia (uma psicose esquizofreniforme com preservação da organização mental) aquela que mais produz delírios místicos. Relata casos de pacientes com demência precoce com idéias de natureza místico-erótica e comenta como o delírio místico nos melancólicos, geralmente envolto em idéias de auto-acusação, é das formas mais graves de delírio religioso. No final, descreve dois casos de auto-amputação do pênis perpetrados por jovens com delírios místicos e exagerados sentimentos religiosos (Cezar, 1939). ${ }^{8}$

Em trabalhos posteriores, Cezar $(1949,1951)$ revisitou o tema da arte dos alienados e sua religiosidade. No primeiro, analisou em detalhes a arte mística de um imigrante português, internado no Juquery desde 1898, caso em que o simbolismo étnico do artista revelaria um erotismo disfarçado em mística. No

8. Um deles, jovem presbiteriano, teve alucinações e delírios acreditando ser o apóstolo Pedro. Após um período em que se tornou triste e sombrio, decidiu cortar o pênis com uma faca, pois se masturbava com freqüência e resolvera seguir as indicações de Jesus, citando para justificar seu ato automutilatório: “Se tua mão direita te escandaliza, corta-a e lança-a fora ...”. O outro jovem delirante que amputou o próprio pênis também era um assíduo masturbador; tendo recebido uma estrita educação católica, considerava a masturbação e a fornicação os pecados máximos; movido por suas análises delirantes, para se liberar de seus desejos eróticos, decidiu também pela amputação do órgão que mais lhe parecia relacionado com seus impulsos pecaminosos (Cezar, 1939). 


\begin{tabular}{cccccc|l}
$R \quad E \quad V$ & I & T & $A$ \\
LATIN O A M ERIC A N A & \\
DE PSICO PATO LOGIA & \\
F U N D A M E N T A L & \\
ano X, n. 1, mar/ 2007 & \\
\hline
\end{tabular}

segundo estudo citado, investigou também em profundidade a composição temática dos desenhos de dois pacientes esquizofrênicos e analisou a mescla de simbolismo cristão e sexual presente nessas obras. Nesse último texto, ele empregou o método psicanalítico na análise dos trabalhos artísticos, considerando a existência, da mesma forma que nos sonhos, de "conteúdos manifestos" e de “conteúdos latentes” a considerar nos desenhos ali enfocados (Cezar, 1951).

As relações entre simbolismo cultural e religioso e simbolismo individual, sexual, foram analisadas num trabalho especialmente feliz, escrito em parceria com Roger Bastide, "Pintura, loucura e cultura” (1956), aqui republicado, e de que trataremos adiante.

Finalmente, destacamos um trabalho de análise histórica, "Demonologia" (1957) em que Cezar discutiu a importância da possessão demoníaca na cultura européia e como tais possessões passaram a fazer parte da expressão da doença mental no Ocidente. Ali, utilizando autores como Charcot, Richer, Janet e Zilboorg, traçou pontos de contato entre a chamada demonopatia e a grande histeria descrita pelos autores europeus.

\section{Roger Bastide}

Ainda que o objetivo principal de nosso artigo seja apresentar aspectos biográficos e bibliográficos de Osório Cezar, não poderíamos deixar de destacar a relevante contribuição do intelectual francês Roger Bastide (1898-1974), sobretudo no que se refere às relações entre saúde mental e religiosidade.

Bastide viveu no Brasil por 16 anos, lecionando sociologia na Universidade de São Paulo entre 1938 e 1954 (Peixoto, 2001). Como declarou um de seus ex-alunos, ${ }^{9}$ a influência de Bastide sobre seus discípulos foi marcante no que se referia à paixão pela pesquisa de campo; a sua sólida, extensa e eclética formação intelectual levava à sala de aula discussões estimulantes e, além de tudo, sua postura crítica com relação ao racionalismo ou "objetivismo" dominantes nas ciências conduzia-o a caminhos algo heterodoxos: "Bastide 'remava contra a maré’” (Cardoso, 2001, p. 18).

9. O ex-presidente Fernando Henrique Cardoso, que foi ainda professor assistente de Bastide na cátedra de Sociologia da USP, dá o seguinte depoimento: “Quantas vezes, com Bastide, andei pelos cortiços e favelas, entrevistando gente pobre, negros, mulatos, mulheres e homens, sobre a vida cotidiana, os preconceitos de cor e de raça, as religiões? Ou (...) andei pelos asilos de loucos pobres (o Juqueri) para que ele escrevesse seus artigos inovadores?” (Cardoso, 2001, p. 16). 
Escritor prolífico, estima-se que tenha deixado mais de 1.300 textos (muitos ainda inéditos), entre livros, artigos em periódicos científicos, resenhas, prefácios, conferências e escritos em jornais e revistas (Ravelet, 2001); parte significativa dessa obra foi dedicada ao estudo da cultura e da sociedade brasileiras, especialmente às relações raciais e às religiões afro-brasileiras, assim sendo, destacaremos apenas uma pequena parte dessa vasta produção.

Desde o início de sua carreira docente (era licenciado em filosofia), na década de 1920, Bastide publicava estudos relacionados à arte e à religiosidade, como o artigo "Mysticisme et sociologie" (1928) ou o livro Les problèmes de la vie mystic (1931).

No período em que esteve no Brasil, escreveu (em português) também crítica literária e de artes plásticas, e sobre psicanálise ("Pintura e mística”, 1938; Psicanálise do cafuné, 1941; Arte e sociedade, 1945; Poetas do Brasil, 1946; Sociologia e psicanálise, 1948; “A psiquiatria social”, 1954).

De volta à França, manteve suas ligações intelectuais e afetivas com o Brasil e com a África, e dedicou-se ainda ao ensino da sociologia e etnologia psiquiátricas; então publicou, entre outros, Relações entre brancos e negros em São Paulo (em co-autoria com Florestan Fernandes, 1955), Brasil, terra de contrastes (1957), O candomblé da Bahia (1958), As religiões africanas no Brasil (1960) e Sociologie des maladies mentales (1965).

\section{Saúde mental e religião em duas obras de Bastide}

Destacaremos aqui dois livros de Roger Bastide, Le candomblé de Bahia (1958), traduzido para o português em 1961, e Sociologie des maladies mentales (1965), editado aqui em 1967.

No primeiro, um belíssimo estudo etnográfico, ele toma o candomblé como uma verdadeira religião (e não como um conjunto de superstições alinhavadas) e, mais ainda, o pensamento africano como pensamento culto e complexo, realizando uma delicada pesquisa que explicita que os cultos "subtendem uma psicologia, uma cosmologia e uma teodicéia” africanas trazidas para o Brasil e repleta de sentidos positivos para os praticantes (Bastide, 2001, p. 24).

Tal abordagem permitiu a Bastide conhecer em profundidade os cultos afrobrasileiros, e as experiências mediúnicas que neles ocorrem, concluindo que esses estados de transe e possessão são mais bem compreendidos pelo entendimento antropológico de seus símbolos e ritos do que por uma aproximação psicopatológica estrita. 


$R$ E V I S T A
LATINOA A M RICANA
DE PSICOPATO LOGIA
FU N D A M E N T A L
anO X, D. 1, mar/2007

Na brilhante análise que faz do transe no contexto da possessão pelos deuses do candomblé, assinala que a dança tem um caráter ritual e teatral, é uma "ópera fabulosa” em que os participantes interagem de acordo com cenas míticas revividas na ocasião, em êxtases que se comunicam, num diálogo de mímicas. Algo que ele denomina metaforicamente de transe intermental: “... um jogo bem regulamentado em que vários transes, complementares uns dos outros, intervêm e se respondem, formando um conjunto de estímulos e de respostas adequadas que segue um cenário imposto pela tradição mítica” (idem, p. 190).

Em seu livro Sociologia das doenças mentais (1967) analisa a relação entre o fato de pertencer a distintas denominações religiosas e o adoecimento mental. Após revisar detalhadamente a literatura da época, conclui que os valores e normas que constituem a cultura religiosa de um grupo étnico atuam e dão a sua contribuição à ocorrência das doenças mentais. Salienta ele que há, entretanto, uma variação dessas normas culturais segundo as classes sociais.

Bastide dá particular atenção à influência das seitas religiosas sobre os transtornos mentais. Para ele, há seitas que desempenham um papel positivo de proteção em relação aos transtornos mentais; outras, entretanto, intensificam “os conflitos psíquicos entre o desejo de perfeição absoluta e os instintos, mais particularmente o instinto sexual” (p. 186). Aqui, possivelmente, Bastide se referia a pequenas igrejas evangélicas, pentecostais, com seu pietismo e moralismo estrito.

Ao analisar outro grupo de pequenas seitas, que ele denomina "seitas urbanas e esotéricas” (grupos de espiritismo híbrido, com componentes afro-brasileiros e kardecistas), diz que tais seitas chamam para seu seio "todos os ansiosos e deprimidos, os grandes vencidos da sociedade industrial; elas constituem verdadeiros caldos de cultura dos transtornos psiquiátricos, os quais elas exaltam, enquanto que as Igrejas os controlavam e reprimiam” (p. 186).

De toda forma, é muito interessante a forma como o autor salienta a variabilidade dos tipos de vida religiosa e a multiplicidade de efeitos sobre a saúde e os transtornos mentais. Para ele, há tipos de vidas religiosas que "nos aproximam das perturbações mentais enquanto outros nos afastam deles; há uma vida religiosa que é regressiva e patológica, existe outra que é progressiva e formadora de personalidades sadias” (p. 186-7).

A conclusão final que Bastide extrai de seus estudos é de que há uma certa autonomia da patologia mental em relação à religião. Para ele a doença mental precede a religião, podendo influir sobre ela e ser por ela influenciada; afirma: “mas quem não vê então que é a doença ou a sanidade que é anterior à religião? As neuroses podem transformar a religião numa construção patológica e as psicoses podem alimentar-lhe os delírios. Mas não é a religião que cria umas ou outras” (p. 187). 
Segundo ele, a psicopatologia, os desequilíbrios familiares e, sobretudo, a “desumanidade das relações industriais” são os fatores que podem contribuir para uma certa degeneração da vida religiosa em neurose. Por outro lado, Bastide defende que o "espírito comunitário, a disciplina das Igrejas e o controle da vida afetiva do homem” (p. 188) poderiam prover uma vida mais sadia às populações.

Moreira-Almeida e colaboradores (2005) reviram recentemente a história da chamada "loucura espírita” na primeira metade do século XX, no Brasil. Naquele contexto, alienistas eminentes como Henrique Roxo, Francisco Franco da Rocha e Afrânio Peixoto consideravam que as práticas “espíritas” (religiões mediúnicas em geral) desencadeavam com freqüência quadros de loucura e histeria. Até os anos de 1950 essa tese foi fortemente sustentada, em particular por Pacheco e Silva, líder universitário da psiquiatria paulista.

Nas décadas seguintes, por influência de trabalhos como os de Roger Bastide e de Osório Cezar, bem como dos psiquiatras Aníbal Silveira, René Ribeiro, Alberto Lyra e Álvaro Rubim de Pinho, tal visão foi sendo paulatinamente substituída por uma percepção menos preconceituosa por parte dos médicos (Dalgalarrondo, 2006).

\section{A arte primitiva nos alienados (1924)}

Nesse artigo, Cezar (1924) relata detalhadamente o caso de um homem negro, de 32 anos, soldado da polícia, casado, católico, que havia sido encaminhado, em 1919, da Cadeia Pública para a internação no Hospício de Juquery porque, movido por intensa atividade delirante, assassinara sua mulher a machadadas. Esse homem, que dizia se comunicar com os "poderes espirituais do espaço” e se intitulava médico - de parca educação formal e que jamais recebera noções de arte - demonstra no hospital prazer especial e incrível habilidade em produzir esculturas originais e muito expressivas e, segundo o psiquiatra: “As suas produções escultóricas giram todas num idêntico princípio: o feiticismo, e em algumas delas deixam reproduzir o sentimento atávico evocando a alma dos antepassados de sua raça” (p. 112-13).

Esse escultor produzira uma obra que chamara de "São Jacinto" e que, segundo ele, era um feitiço, pois a imagem fora construída "com o ouro mais puro da mina que encontrei no terreiro e ela possui a virtude de espalhar a felicidade entre os homens” (p. 115). Chamava ainda a atenção a forma como o artista modelara as mãos de outra estátua sua, chamada de "Santo Antonio da Rocha” e o simbolismo sexual e religioso que o alienista nelas percebeu. Notando nesse delirante um verdadeiro artista cubista, Cezar afirma que em suas obras 
se encontrariam “... além de um sentimento artístico feiticista, recordações de atos de sua infância, que surge do subconsciente e que ele plasma no barro sob a forma de símbolo” (p. 123).

Conforme mencionamos, Osório Cezar (citando o antropólogo Tylor) aqui utiliza conceitos da antropologia evolucionista, que considerava haver algumas etapas inescapáveis a que todos os povos estariam sujeitos em seu desenvolvimento cultural, sendo tais etapas da vida religiosa: o antropomorfismo, o animismo difuso, o animismo concentrado, o fetichismo (ou feiticismo, como prefere Cezar - um animismo que atribuía a cada ser e a cada coisa uma alma, um espírito independente do corpo), o politeísmo e o monoteísmo (Poirier, 1981).

De acordo com essa teoria, a fase evolutiva em que se encontrava a maioria dos povos negros africanos não permitiria que sua religiosidade fosse além do fetichismo; os “feitiços” eram objetos de culto, dotados de poderes mágicos. Mesmo sendo brasileiro, esse descendente de africanos carregaria em si tal condição mental, que por meio do atavismo ressurgiria das profundezas subconscientes, junto às recordações pessoais do doente.

Neste ponto, associam-se conceitos da antropologia evolucionista e da psicanálise, algo que fazia muito sentido na época. A premissa utilizada - na ocasião já em vias de perder seu status de conceito científico válido - era que “a ontogenia repete a filogenia”, ou seja, a noção de atavismo baseada na chamada teoria da recapitulação de Haeckel. ${ }^{10}$

Também não causa espanto que esteja presente, ainda que de passagem, a teoria da degenerescência; ${ }^{11}$ o autor menciona na história clínica do escultor: "apresenta diversos estigmas de degeneração, tais como assimetria craniana, orelhas pequenas e abauladas, abóbada palatina funda e pés chatos” (Cezar, 1924,

10. A teoria de Ernest Haeckel afirmava que, durante seu crescimento embrionário, todo indivíduo passaria por fases que repetiriam, de maneira seqüencial, as formas adultas de seus antepassados. S. J. Gould observa que a teoria da recapitulação saiu da biologia para impregnar outras áreas do conhecimento, como a sociologia, a psicologia e a psicanálise, como por exemplo Freud em "Totem e tabu" (Gould, 1999).

11. A partir de 1860, a teoria de B. A. Morel conheceria larga repercussão na França, sendo ali adotada e desenvolvida por muitos autores, e ainda nos países ligados à tradição médica francesa, como o Brasil. Caberia a V. Magnan, a partir da década de 1880, reformular a teoria de Morel e transformá-la segundo os novos moldes evolucionistas, tornando ainda mais onipresentes na medicina as idéias de degenerescência e de hereditariedade mórbida. Entre os alienistas havia concordância de que a degenerescência seria uma importante causa da alienação mental; mas, quanto aos motivos causadores desta degeneração, as opiniões divergiam. No Brasil, por exemplo, a mistura inter-racial, a procriação de mestiços, poderia ser considerada relevante para este processo degenerativo. 
p. 113). Tal degenerescência poderia ser herdada ou adquirida e predisporia à doença mental, e seria diagnosticável através de estigmas físicos, intelectuais, afetivos, morais e comportamentais.

Observe-se que, nas primeiras três décadas do século $\mathrm{XX}$, os conceitos de degenerescência e de atavismo eram ainda populares como teoria etiológica das moléstias mentais, em especial entre os psiquiatras franceses, italianos e brasileiros, ainda que seus exageros fossem denunciados pelos mais críticos $^{12}$ (Oda e Dalgalarrondo, 2001). Por outro lado, uma peculiar articulação entre teoria psicanalítica, teoria da degenerescência e higienismo foi feita por alguns psiquiatras brasileiros, como Henrique Roxo (Facchinetti e Venancio, 2006).

Como veremos a seguir, Osório Cezar utilizará outros referenciais antropológicos e etnopsicológicos no artigo de 1956, afinados aos avanços desses campos, abandonando os pressupostos evolucionistas e trabalhando a idéia de cultura de forma mais refinada; vale ressaltar que ali os autores problematizam a crença - que circula ainda hoje - de que a arte dos doentes mentais é sempre próxima àquela dos povos primitivos e das crianças (Bastide e Cezar, 1956).

\section{Pintura, loucura e cultura (1956)}

Nesse trabalho a quatro mãos, Bastide e Cezar discutem as relações entre imigração e perturbações mentais, analisadas a partir da produção artística de estrangeiros internados no Juquery. Estão presentes no texto também hipóteses sobre as complexas conexões entre indivíduo, cultura e sociedade, em perspectivas antropológica e psicanalítica.

Os autores partem do princípio de que haveria estratificações no conjunto da personalidade, sendo que a doença mental permitiria separar o que chamam de "personalidade básica” (aquela formada na primeira infância) de suas superestruturas; neste ponto, eles rejeitam a idéia (vinda de uma psicopatologia evolucionista) de que a desagregação da personalidade na doença mental atingisse primeiramente a “personalidade cultural”, por ser esta supostamente mais recente,

12. Por exemplo, já em 1905, Juliano Moreira e Afrânio Peixoto recusavam a noção de atavismo e davam muito mais importância à educação e às condições gerais de vida no desencadear das doenças mentais; sobre a ação da degeneração tinham certa ambigüidade: afirmavam ser ela "a leira preparada para o cultivo de todas as aberrações”, todavia reconhecendo que tal noção era ampla demais, “por não ter sido esclarecida sua intimidade mórbida”. Veja-se Moreira, J. e Peixoto, J. A paranóia e as síndromes paranóides. Revista Latinoamericana de Psicopatologia Fundamental, v. IV, n. 2, p. 134-167, jun./2001. 


\begin{tabular}{cccccc|l}
$R \quad E \quad V$ & I & T & $A$ \\
LATIN O A M ERIC A N A & \\
DE PSICO PATO LOGIA & \\
F U N D A M E N T A L & \\
ano X, n. 1, mar/ 2007 & \\
\hline
\end{tabular}

recordando que "a cultura começa desde a mais tenra idade, para prosseguir durante todo o curso da vida” (Bastide e Cezar, 1956, p. 51).

Detendo-se especialmente nas obras pictóricas de três imigrantes (um alemão, um espanhol e um português) alienados, os autores propõem uma forma de ligação entre os diversos simbolismos individuais e os culturais, pois:

A cultura não é externa ao indivíduo; ela existe pela educação interiorizada e, conseqüentemente, assume colorido variável, de acordo com os indivíduos. A arte, sendo a expressão da personalidade, seja essa personalidade normal ou patológica, a pintura não nos colocará jamais senão em presença da cultura introvertida e mais ou menos deformada pelos problemas do homem que pinta. (p. 52)

Haveria, portanto uma estreita relação entre os “estilos patológicos” e os “estilos culturais”. Para eles, existiria quase sempre uma fusão original, variável de indivíduo para indivíduo, entre o símbolo libidinoso e o símbolo cultural, freqüentemente religioso. No imigrante, em particular, haveria processos de recalcamento e de recuperação dos símbolos da cultura de origem e da cultura atual, que deveriam ser decodificados, posto que o "elemento cultural autóctone é, de início, um símbolo-sinal, um meio de restabelecer a comunicação tornada impossível ou difícil sobre a nova terra, com os homens da pátria dos antepassados" (p. 56).

Bastide e Cezar destacam ainda um outro ponto que julgam relevante nos doentes mentais imigrantes: a cultura se manifestaria como sinal de um estado de tensão. Afirmando que nem sempre o chamado "choque cultural” (o sofrimento advindo das dificuldades de adaptação à nova pátria, devido a diferenças culturais pronunciadas) estaria na origem das perturbações mentais; os autores sugerem relações dinâmicas entre esse dito choque e os conflitos pessoais (infantis) ou sociais (como a discriminação étnica), que poderiam preponderar como elementos desencadeantes da doença, conforme os recursos psíquicos dos indivíduos.

Como ressaltam os autores, ao considerar as obras de arte dos alienados manifestações da linguagem, ainda que de uma linguagem peculiar e estranha, passa-se a admitir que aqueles não seriam tão “alienados” assim, isto é, manteriam sua inserção na(s) cultura(s) através da expressão artística, possibilitando alguma chance de comunicação, de compreensão e de cura.

\section{Referências}

Amaral, A. A. Tarsila: sua obra e seu tempo. São Paulo: Perspectiva/Edusp, 1975. Andriolo, A. A “psicologia da arte” no olhar de Osório Cezar: leituras e escritos. Psicol. 
cienc. prof. [on-line]. vol. 23, n. 4, dez. 2003, p. 74-81. <http://scielo.bvs-psi.org.br/ scielo.php?script=sci_arttext\&pid=S1414-98932003000400011\&lng=es\&nrm=iso $>$. Acesso em 10 de janeiro de 2007.

BAstide, R. Sociologia das doenças mentais. São Paulo: Companhia Editora Nacional, 1967. [Sociologie des maladies mentales, 1965].

O candomblé da Bahia: rito nagô. Trad. de Maria Isaura Pereira de Queiroz. Revisão técnica de Reginaldo Prandi. São Paulo: Companhia das Letras, 2001. [Le candomblé de Bahia: rite nagô, 1958].

Bastide, R. e Cezar, O. Pintura, loucura e cultura. Arquivos do Departamento de Assistência a Psicopatas do Estado de São Paulo, v. 22, p. 51-70, 1956. [Republicado em Revista Brasiliense, n. 19, 1958].

Cardoso, F. H. Comentário. In: Bastide, R. O candomblé da Bahia: rito nagô. São Paulo: Companhia das Letras, 2001. p. 15-19.

CezAr, O. A arte primitiva nos alienados: manifestação escultórica com caráter simbólico feiticista num caso de síndrome paranóide. Memórias do Hospício de Juquery, v. I, n. 1, p. 111-125, 1924.

Contribuição para o estudo das glândulas de secreção interna na demência precoce. Memórias do Hospital de Juquery, v. V-VI, n. 5-6, p. 119-143, 1928-1929.

A expressão artística nos alienados (contribuição para o estudo dos símbolos na arte). São Paulo: Oficinas Gráficas do Hospital de Juquery, 1929.

1932.

Onde o proletariado dirige... (visão panorâmica da URSS). São Paulo: s/ed.,

Que é o estado proletário? Reflexões sobre a Rússia Soviética. São Paulo: Empresa Gráfica Revista dos Tribunais, 1933.

Misticismo e loucura: contribuição para o estudo das loucuras religiosas no Brasil. São Paulo: Oficinas Gráficas do Serviço de Assistência a Psicopatas, 1939.

Simbolismo místico nos alienados. Revista do Arquivo do Município de São Paulo, n. 124, p. 47-72, 1949.

Contribuition à l'étude de l'arte chez les aliénés. Arquivos do Departamento de Assistência a Psicopatas do Estado de São Paulo, v. XVI, n. único, p. 51-64, 1951.

Demonologia. Arquivos do Departamento de Assistência a Psicopatas do Estado de São Paulo, v. XXIII, p. 137-148, 1957.

Cezar, O.; Monteiro, J. P. Contribuição ao estudo do simbolismo místico nos alienados (um caso de demência precoce paranóide num antigo escultor). São Paulo: Hélios, 1927.

Dalgalarrondo, P. Religião e psicopatologia: relações entre religiosidade, saúde e transtorno mental. Tese de concurso (professor titular). Faculdade de Ciências Médicas da Unicamp, Campinas, 2006. 
Facchinetti, C. e Venancio, A. T. A. Entre a psicanálise e a degenerescência: sexualidade e doença mental no início do século XX no Brasil. Revista Latinoamericana de Psicopatologia Fundamental, v. IX , n. 1, p. 151-161, mar./2006.

Ferraz, M. H. C. T. Arte e loucura: limites do imprevisível. São Paulo: Lemos, 1998.

Gould, S. J. A falsa medida do homem. 2. ed. São Paulo: Martins Fontes, 1999. p. 111-14.

Marcondes, D.; Cezar, O. Sobre dois casos de estereotipia gráfica com simbolismo sexual. Memórias do Hospício de Juquery, v. III-IV, n. 3-4, p. 161-165, 1927.

Moreira-Almeida, A. et al. History of "Spiritist Madness" in Brazil. History of Psychiatry, v. 16, n. 1, p. 5-25, 2005.

Nosek, L. et al. Álbum de família: imagens, fontes e idéias da psicanálise em São Paulo. São Paulo: Casa do Psicólogo, 1994.

Oda, A. M. G. R. e Dalgalarrondo, P. A paranóia, segundo Juliano Moreira e Afranio Peixoto. Revista Latinoamericana de Psicopatologia Fundamental, v. IV, n. 2, p. 125133, jun./2001.

Oliveira, C. L. M. V. de. História da psicanálise - São Paulo (1920-1969). São Paulo: Escuta, 2005.

Peixoto, F. A. A utopia africana de Roger Bastide. In: Bastide, R. O candomblé da Bahia: rito nagô. São Paulo: Companhia das Letras, 2001. p. 7-13.

Poirier, J. História da etnologia. Trad. de Ivone Toledo. São Paulo: Cultrix/Edusp, 1981. p. 46-47.

Ravelet, C. Bibliografia parcial. In: Bastide, R. O candomblé da Bahia: rito nagô. São Paulo: Companhia das Letras, 2001. p. 357-364.

\section{Resumos}

Este artículo trata de los momentos históricos del estudio de las relaciones entre arte, religión y psicopatología; en este sentido, analizamos las textos "El arte primitivo en los alienados" (Osório Cezar, 1924) y "Pintura, locura y cultura” (Roger Bastide y Osório Cezar, 1956).

En Brasil, Osório Cezar, médico del hospital Juquery, fue el primero investigador que tomó como objeto de estudio el arte producido por enfermos mentales.

Roger Bastide, intelectual francés que vivió en Brasil, autor prolífero, entre otros relevantes aportes nos legó estudios seminales en los campos de la sociología de las enfermedades mentales y de la etno-psiquiatría.

Palabras claves: Arte, locura, religión y psicopatología, Roger Bastide, Osório Cézar 
Cet article se concentre sur deux moments historiques des études sur les rapports entre l'art, la religion et la psychopathologie. À cette fin, nous analysons les textes "L'art primitif chez les aliénés" (Osório Cezar, 1924) et "Peinture, folie et culture" (Roger Bastide et Osório Cezar, 1956).

Au Brésil, Osório Cezar, médecin de l'Hôpital de Juquery (São Paulo) a été le premier chercheur à analyser l'art des malades mentaux.

Roger Bastide, penseur français qui a vécu au Brésil et auteur prolifique, nous a légué des contributions très importantes pour la sociologie des maladies mentales et l'ethnopsychiatrie.

Mots clés: Art et folie, religion et psychopathologie, Roger Bastide, Osório Cezar

This article presents an overall view of two historical periods of the study of the interface between art, religion and psychopathology. Here we intend to review the texts: "The primitive art of the insane" (Osório Cezar, 1924) and "Painting, madness and culture" (Roger Bastide and Osório Cezar, 1956).

Osório Cezar, a physician at the Juquery Hospital in São Paulo, was Brazil's first researcher to analyze art produced by mentally ill persons.

Roger Bastide, a prolific French intellectual who lived in Brazil, contributed greatly to the theoretical progress of the sociology of mental illness and ethnopsychiatry.

Key words: Art and madness, religion and psychopathology, Roger Bastide, Osório Cezar

Versão inicial recebida em janeiro/2007

Aprovado para publicação em janeiro/2007 